\title{
DNA Synthesis Without Base Protection
}

An ultimate goal in the chemical synthesis of DNA is the ability to form O-selective internucleotide bonds without the use of baseprotecting groups, as can be done by enzymatic synthesis using DNA polymerases. The current chemical synthesis of DNA fragments requires multistep procedures for the introduction and removal of protecting groups to guarantee the fidelity of the synthesis (Caruthers, 1991). Satisfactory results have in fact been reported for the synthesis of unmodified DNA oligomers (UNIT 3.1). In these post-genome days, however, there are increasing demands to accelerate manipulation for gene detection and diagnosis, so that it is increasingly desirable to find more straightforward methods for the synthesis of DNA fragments (Shena, 1999). For this purpose, a number of improvements in the widespread phosphoramidite approach, which is used as the most reliable method, have been reported (Beaucage and Iyer, 1992; UNIT 3.3). They involve the use of more base-labile $N$-phenoxyacetyl protecting groups (Schulhof et al., 1987) and methylamine (Boal et al., 1996) as a powerful deacylating reagent for rapid deprotection, as well as the use of protecting groups that can be removed under neutral conditions (Hayakawa et al., 2001). As an alternative to these types of improvements, O-selective internucleotide bond formation provides an entirely different approach; the methods described here will offer new insight into modern DNA synthesis.

The feasibility of O-selective internucleotide bond formation using non- $\mathrm{N}$-acylated nucleoside derivatives has been suggested based on the unique properties of the amino and hydroxy groups of nucleosides. Baddiley and Todd (1947) reported that $2^{\prime}, 3^{\prime}$ $O$-isopropylideneadenosine underwent $5^{\prime}-O$ selective phosphorylation with dibenzyl phosphorochloridate in pyridine (Fig. 3.10.1). In phosphorylation of nucleosides, it is well known that phosphorus oxychloride selectively reacts with nucleosides in triethyl phosphate to give 5'-O-phosphorylated nucleosides (Yoshikawa and Kato, 1967; Ikemoto et al., 1995). Partial acetylation of adenosine with acetic anhydride gives 3',5'-di- $O$ acetyladenosine (Kool et al., 1987). Silylation of deoxyribonucleotides gives exclusively Osilylated products (Ogilvie, 1973; Sekine et al.,
1985). In contrast, it was also reported that deoxycytidine underwent selective $\mathrm{N}$-acylation with various acylating reagents (Watanabe and Fox, 1966; Nikolenko et al., 1967; Hata and Kurihara, 1973). These apparently contradictory results could be explained through a comprehensive understanding that the difference in reactivity between the hydroxy and amino groups of nucleosides varies depending on the inherent Soft-Hard (Pearson, 1987, 1990) nature of nucleobases and electrophilic reagents, as well as reaction conditions such as solvents and additives. Therefore, to realize oligonucleotide synthesis without base protection, it is important to create the most reasonable intermediates that are capable of $\mathrm{O}$-selective phosphorylation in the reaction system.

\section{LIQUID-PHASE SYNTHESIS}

Several precedents concerning oligonucleotide synthesis without $\mathrm{N}$-protecting groups have been reported for liquid-phase oligonucleotide synthesis (Fig. 3.10.1). Using his original phosphite triester approach (Yuodka et al., 1976), Letsinger found that the amino group of the adenine base moiety exhibited rather poor reactivity toward tervalent phosphitylating intermediates (Letsinger et al., 1976; Finnan et al., 1980). Using this method, these investigators synthesized an oligonucleotide with the sequence TAAAT. Adamiak reported the synthesis of tRNA anticodon loop fragments containing ureidonucleosides without protection of the adenine moiety by using 2,4,6triisopropylbenzensulfonyl $1 H$-tetrazolide as the condensing reagent in the phosphotriester approach (Adamiak and Stawinski, 1977; Adamiak et al., 1978). Fourrey and Varenne (1985) reported the synthesis of DNA dimers using N-unprotected $\mathrm{dA}$ and $\mathrm{dC}$ phosphoramidite building blocks with 2-chlorophenyl and morpholino groups. Hayakawa reported several methods for activation of alcoholic components by use of metalating reagents such as $t$-BuLi (Hayakawa et al., 1983a), $t$ $\mathrm{BuMgCl}$ (Hayakawa et al., 1984, 1985), and $\mathrm{LiAl}\left(\mathrm{NiPr}_{2}\right)_{4}$ (Hayakawa et al., 1983b). These agents accelerate displacement with active esters of nucleoside phosphotriester components without introduction of any protecting groups on the adenine base. 


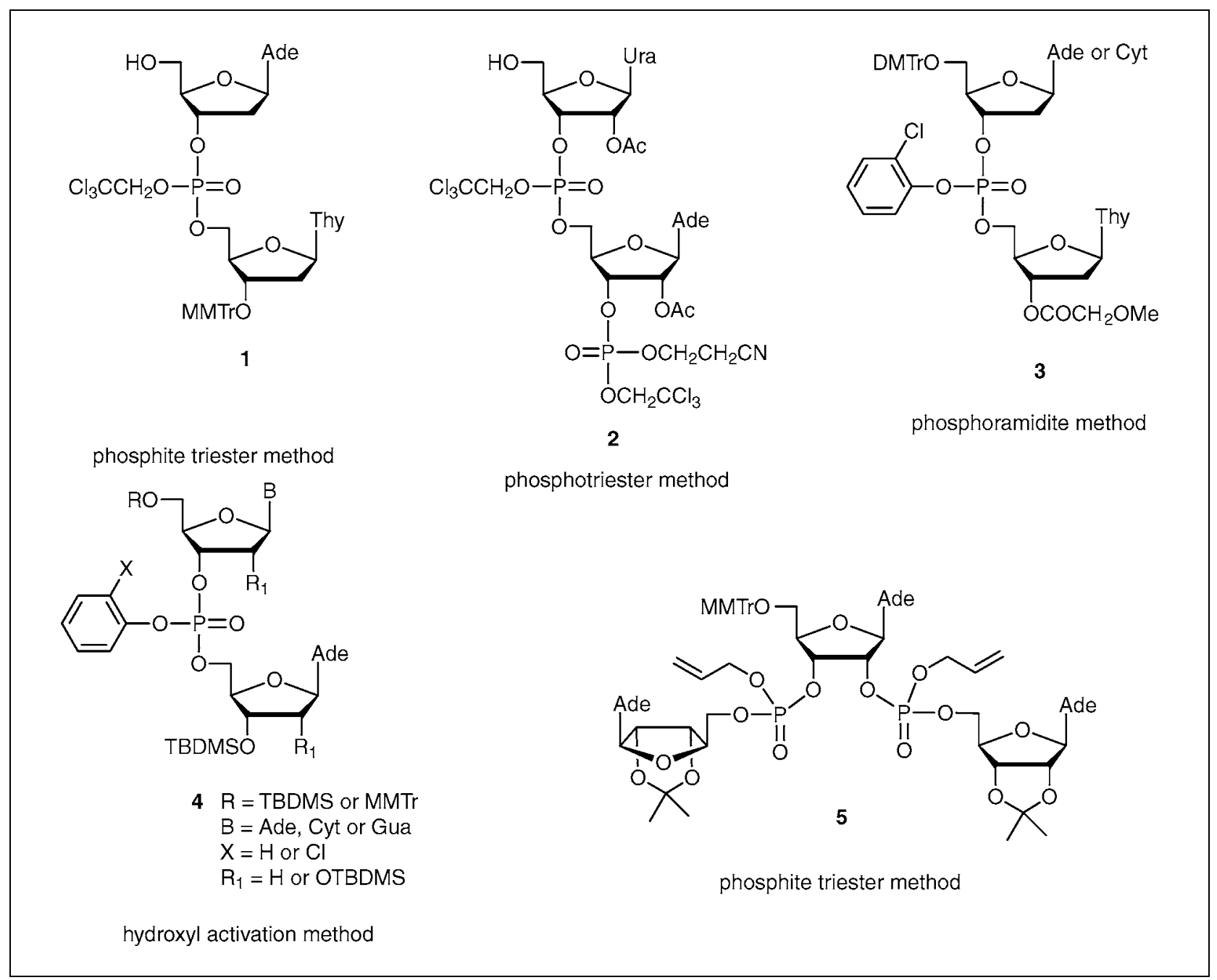

Figure 3.10.1 Structure of oligonucleotide derivatives obtained by liquid-phase synthesis without base protection. Abbreviations: Ade, adenin-9-yl; Cyt, cytosin-1-yl; DMTr, 4,4'-dimethoxytrityl; Gua, guanin-9-yl; MMTr, 4-monomethoxytrityl; TBDMS, tert-butyldimethylsilyl; Thy, thymin-1-yl; Ura, uracil-1-yl. References: (1) Letsinger et al. (1976); (2) Adamiak and Stawinski (1977); (3) Fourrey and Varenne (1985); (4) Hayakawa et al. (1983a,b, 1984); (5) Hayakawa et al. (1987).

DNA Synthesis

Without Base

Protection

\subsection{0 .2}

\section{SOLID-PHASE SYNTHESIS USING THE PHOSPHORAMIDITE APPROACH}

\section{Synthesis of Common Starting Nucleosides}

\section{5'-O-Dimethoxytrityldeoxyribo- nucleosides}

There are two methods for the synthesis of deoxyribonucleosides with $5^{\prime}-O-\left(4,4^{\prime}-\right.$ dimethoxytrityl) (DMTr) protection. One is the direct introduction of the DMTr group into deoxyribonucleosides. The $5^{\prime}-O$-selective tritylation of $\mathrm{dC}$ in pyridine gives rise to $5^{\prime}-O$ DMTr-dC in $89 \%$ yield, as first described by Michelson and Todd (1954). Jones reported that direct dimethoxytritylation of $\mathrm{dA}$ with 1.5 equiv of DMTr-Cl in pyridine gave $5^{\prime}-O$ DMTr-dA in 77\% yield (Fig. 3.10.2, method
A), and that the use of 2 equiv of DMTr-Cl for $\mathrm{dC}$ gave $5^{\prime}-O$-DMTr-dC and $5^{\prime}-O, N$-bisDMTr$\mathrm{dC}$ in $32 \%$ and $40 \%$ yields, respectively ( $\mathrm{Ti}$ et al., 1982). Levin and colleagues also reported that dimethoxytritylation of $\mathrm{dA}, \mathrm{dC}$, and $\mathrm{dG}$ gave the corresponding 5'-O-DMTr derivatives in $61 \%, 48 \%$, and $55 \%$ yields, respectively (Levin et al., 1991), although no details were described in the paper.

In connection with $5^{\prime}$ - $O$-selective dimethoxytritylation, Adamiak's early paper concerning $5^{\prime}$-O $O$-selective monomethoxytritylation of $\mathrm{A}, \mathrm{C}$, and $\mathrm{G}$ is quite positive (Okupniak et al., 1981). Reaction of dA, dC, or $\mathrm{dG}$ with 1.2 equiv of 4-monomethoxytrityl chloride (MMTr-Cl) in dimethylformamide (DMF) or dimethyl sulfoxide (DMSO) in the presence of 6-nitroquinoline $\left(\mathrm{p} K_{\mathrm{a}}=\right.$ 2.7) or 3-bromopyridine $\left(\mathrm{p} K_{\mathrm{a}}=2.9\right)$ gave 


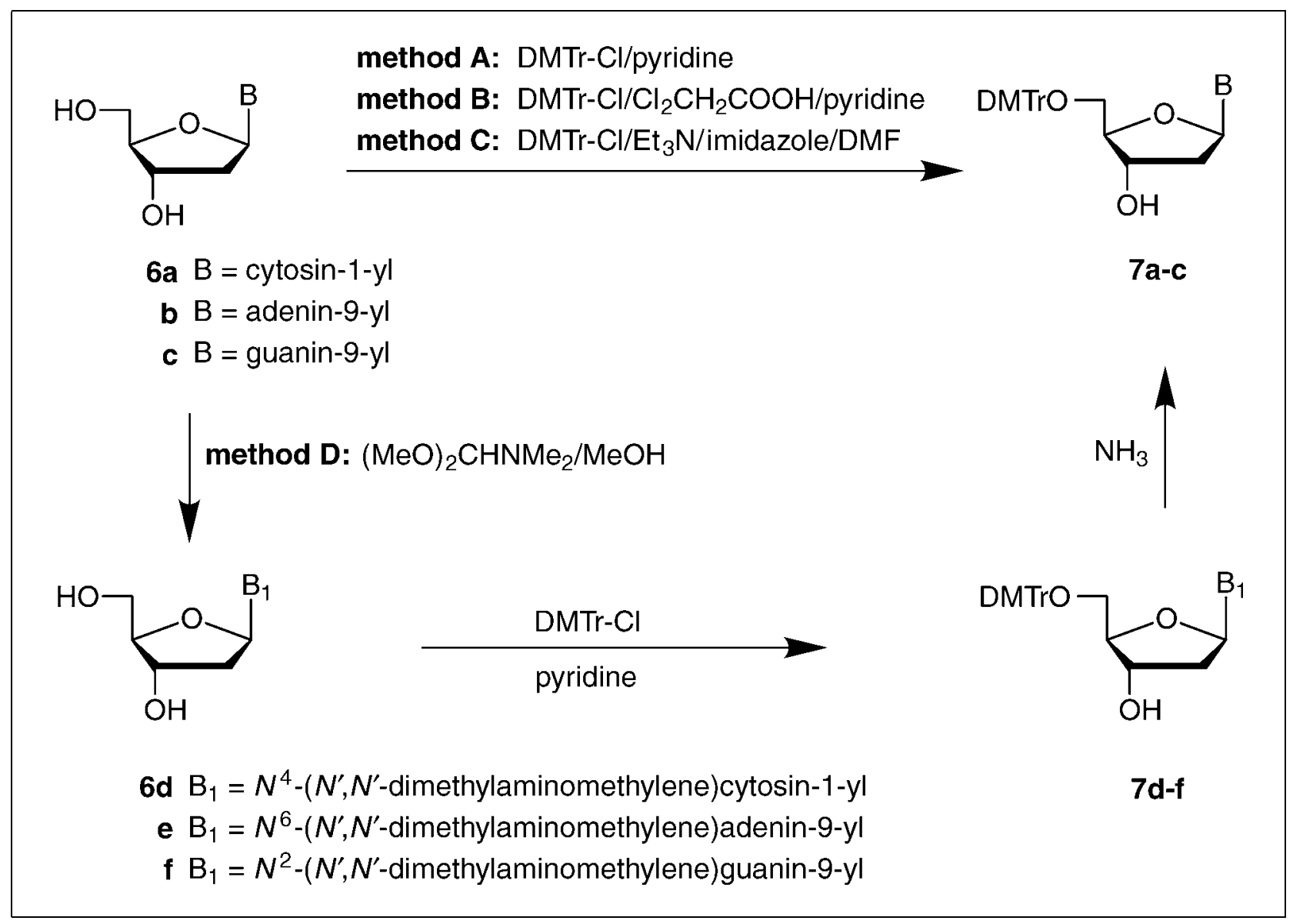

Figure 3.10.2 Synthesis of 5'-O-DMTr- $N$-unprotected deoxyribonucleosides using direct approaches (methods $A$ to $C$ ) or transient dimethylaminomethylene (Dmf) base protection (method D). DMF, dimethylformamide.

$5^{\prime}-O-M M T r-\mathrm{dC}, 55^{\prime}-O-M M T r-\mathrm{dA}$, and $5^{\prime}-O-$ MMTr-dG in $85 \%, 92 \%$, and $66 \%$ yields, respectively. The use of bases that are weaker than the $\mathrm{dA}$ and $\mathrm{dC}$ nucleobases is essential for high $5^{\prime}-O$-selectivity, because the nucleobases must be protonated to be converted to inert species under the reaction conditions used. Further application of this method to a series of deoxyribonucleosides should be studied in the future.

Ishido reported that $5^{\prime}$ - $O$-selective dimethoxytritylation of $\mathrm{dC}$ in the presence of dichloroacetic acid gave $5^{\prime}-O$-DMTr-dC in $71 \%$ yield (Ishido, 1989; Nishino et al., 1991; Fig. 3.10.2, method B). This procedure is applicable to the synthesis of $5^{\prime}-O$-DMTrdA but not 5'-O-DMTr-dG (A. Ohkubo, K. Seio, and M. Sekine, unpub. observ.). Hayakawa reported an improved method for the selective $5^{\prime}$-O-dimethoxytritylation of deoxyribonucleosides using DMTr-Cl/ triethylamine/imidazole in DMF, which gave $5^{\prime}-O$-DMTr-dC, 5'-O-DMTr-dA, and $5^{\prime}-O$-DMTr-dG in $76 \%$ to $85 \%, 82 \%$ to $89 \%$, and $74 \%$ to $78 \%$ yields, respectively (Kataoka and Hayakawa, 1999; Fig. 3.10.2, method C).

A different method employed at an earlier stage by Jones involves transient $\mathrm{N}$ protection with the dimethylaminomethylene (Dmf) group (Froehler and Matteucci, 1983a) by reaction of deoxyribonucleosides with dimethylformamide dimethylacetal (Kung and Jones, 1992; Fig. 3.10.2, method D). Although this approach requires a three-step procedure to obtain the desired $5^{\prime}-O$-DMTrdeoxyribonucleosides, the transient protection and deprotection using the Dmf group proceed cleanly and quantitatively, so that purification is necessary for only the final product. This procedure has proved to be reliable and reproducible.

In the case of $\mathrm{dG}, \quad 5^{\prime}-O, 2-N$ bis(DMTr)deoxyguanosine was used as the precursor of the 3'-phosphoromorpholidite derivative (Fourrey and Varenne, 1985). This ditritylated species can be obtained by reaction of $\mathrm{dG}$ with excess $\mathrm{DMTr}-\mathrm{Cl}$ in pyridine (Schaller et al., 1963).
Synthesis of Unmodified Oligonucleotides

3.10.3 


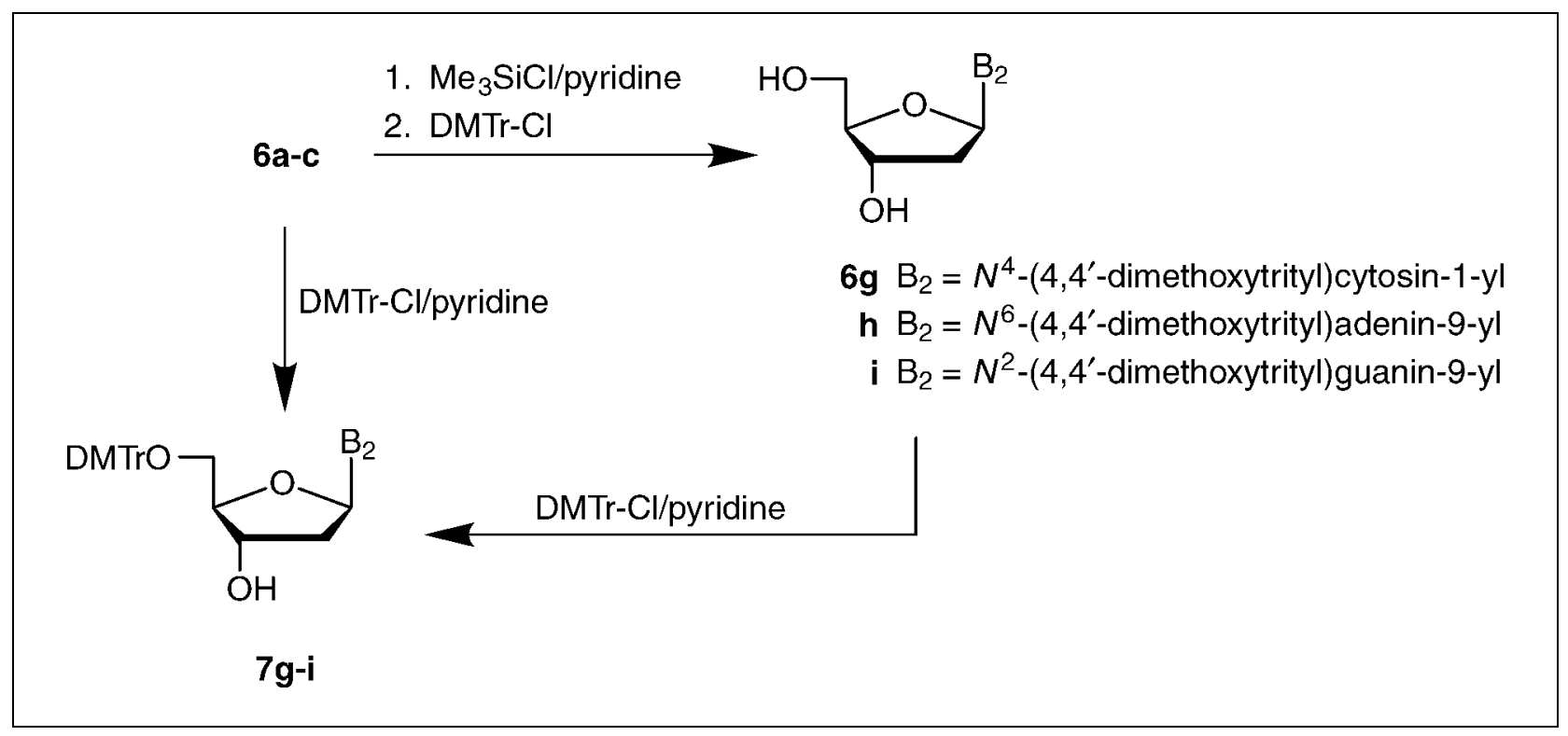

Figure 3.10.3 Synthesis of 5'-O,N-bis(DMTr)deoxyribonucleosides by successive tritylation (right) or direct tritylation (left).

DNA Synthesis

Without Base

Protection

\subsection{0 .4}

\section{$5^{\prime}-\mathrm{O}, \mathrm{N}$-Bis(dimethoxytrityl)deoxyribo- nucleosides for the $3^{\prime}$ terminus}

The general synthesis of oligodeoxyribonucleotides with appropriate sequences requires the synthesis of $3^{\prime}$-terminal deoxyribonucleoside building blocks that can be attached to resins via linkers. To introduce $\mathrm{dA}, \mathrm{dC}$, and $\mathrm{dG}$ into the $3^{\prime}$-terminal site, their $3^{\prime}$-succinate ester derivatives or other equivalents are required. Because succinic anhydride reacts with the nucleobases (Kume et al., 1984), the amino functions of these deoxyribonucleosides should be protected to avoid such side reactions. For this purpose, the best approach is to use $5^{\prime}-O, N$-bis(DMTr)deoxyribonucleoside derivatives (S.7g-S.7i; Fig. 3.10.3). Several approaches have been tested for the synthesis of these compounds. NDimethoxytritylation with DMTr-Cl in the presence of $\mathrm{Me}_{3} \mathrm{SiCl}$ followed by successive $5^{\prime}$-O-dimethoxytritylation (right side of figure) gave $N$-DMTr-deoxyribonucleosides in high yields (Wada et al., 1998b). The direct preparation of these substances from deoxyribonucleosides (left) resulted in complex mixtures including the desired materials.

To introduce these 5'-O,N-bis(DMTr) derivatives onto polymer supports, they were converted to $3^{\prime}$-succinate half-esters, which were linked to resins in situ by condensation using a phosphonium-type condensing reagent, 2-(benzotriazol-1-yloxy)1,1-dimethyl-2-(pyrrolidin-1-yl)-1,3,2diazaphospholidinium hexafluorophosphate
(BOMP; Wada et al., 1997). To mask unreacted amino groups on the resin, careful treatment with suitable acylating reagents is very important. When an $N$-DMTr-dG derivative was treated with acetic anhydride in pyridine in the presence of 4-(dimethylamino)pyridine, complete replacement of the DMTr group with an acetyl group took place (Fig. 3.10.4; Wada et al., 1998b). This inherent side reaction was overcome by using 1-acetylimidazole as the acylating reagent. This reagent did not react with the guanosine moiety but completely reacted with the unreacted amino groups on the resin.

The $N$-DMTr group is generally more stable than the $O$-DMTr group. Complete deprotection for $\mathrm{dA}$ and $\mathrm{dG}$ required only $5 \mathrm{~min}$ when using $1 \%$ trifluoroacetic acid (TFA) in $\mathrm{CH}_{2} \mathrm{Cl}_{2}$. dC derivatives required a more prolonged time of $30 \mathrm{~min}$ for complete removal of the DMTr group using 3\% TFA in $\mathrm{CH}_{2} \mathrm{Cl}_{2}$, but the glycosyl bond of these derivatives is sufficiently stable that this is not a problem. Several short oligodeoxyribonucleotides containing $\mathrm{dA}, \mathrm{dC}$, or $\mathrm{dG}$ at the $3^{\prime}$-terminal site were successfully synthesized using the $H$ phosphonate approach without base protection (Fig. 3.10.5; Wada et al., 1998b). Although the syntheses of relatively longer oligodeoxyribonucleotides (20- to 21-mers) having dG (Gryaznov and Letsinger, 1992; Hayakawa and Kataoka, 1998) and dC (Hayakawa and Kataoka, 1998) at the $3^{\prime}$-terminal position were reported, no details about how to solve the aforementioned problem were described. 


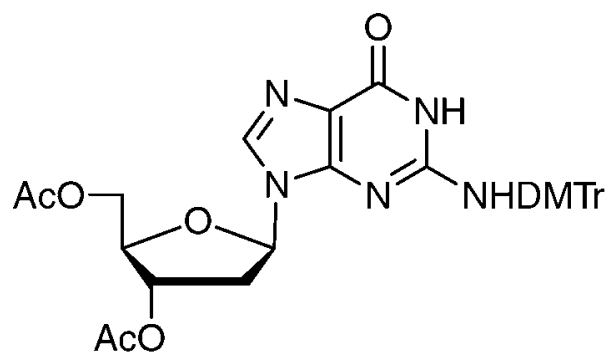

8<smiles>CC(=O)OC[C@@H]1C[C@@H]2O[C@@H](C[C@@H]2OC(C)=O)O1</smiles>

9

Figure 3.10.4 The capping reaction prescribed for masking the unreacted amino groups on the resin also results in an undesired $\mathrm{N}$-acetylation side reaction. This can be prevented by using 1-acetylimidazole (Aclm) instead of acetic anhydride $\left(\mathrm{Ac}_{2} \mathrm{O}\right)$ and 4-(dimethylamino)pyridine (DMAP).

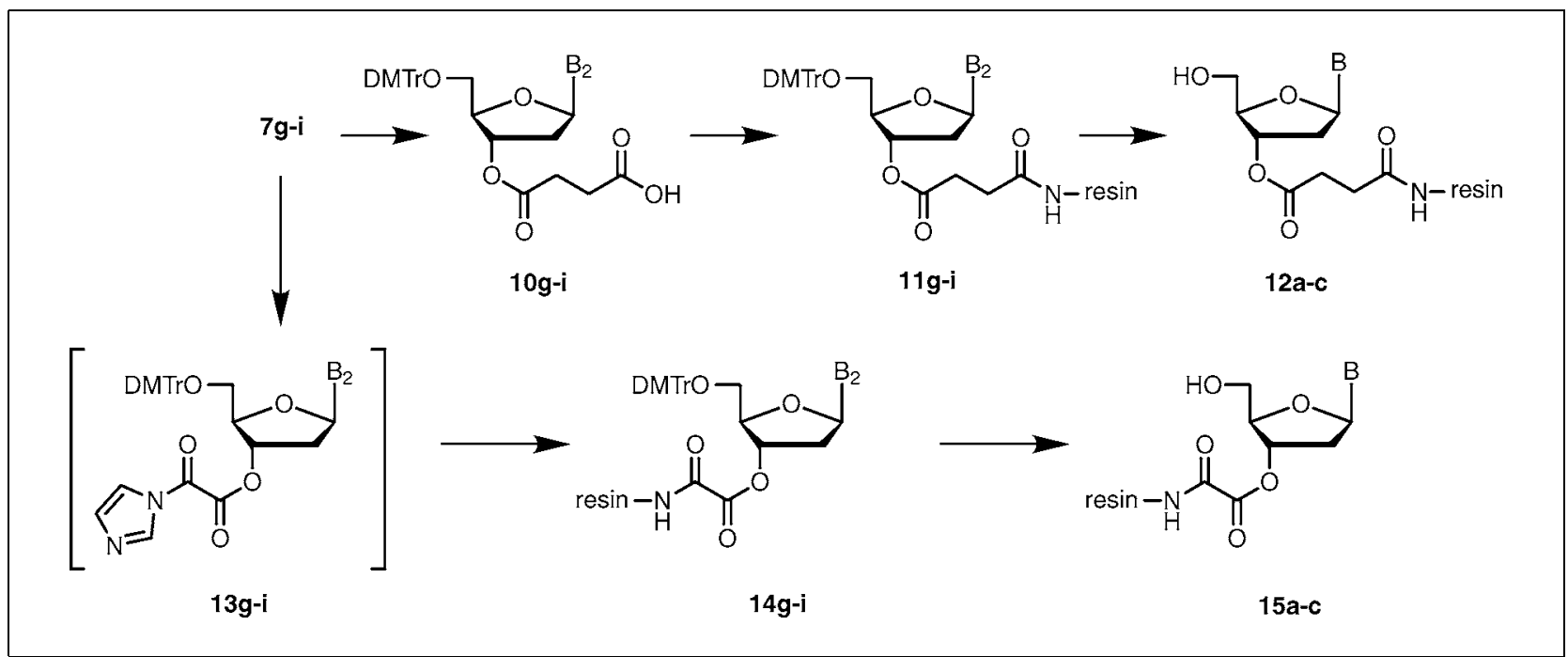

Figure 3.10.5 Synthesis of polymer-supported deoxyribonucleoside monomer building blocks. $\mathrm{B}$ and $\mathrm{B}_{2}$ are unprotected and $\mathrm{N}$-DMTr-protected nucleobases, respectively.

\section{Synthesis of Deoxyribonucleoside 3'-Phosphoramidite Building Blocks}

The $\quad 3^{\prime}$-( $O$-methyl- $N, N^{\prime}$-tetraisopropylphosphoramidite) building blocks of $\mathrm{N}$ unprotected deoxyribonucleosides $(\mathrm{dC}, \mathrm{dA}$, and $\mathrm{dG}$ ) were synthesized in $85 \%$ to $90 \%$ yield by $3^{\prime}-O$-selective phosphitylation of the corresponding $\mathrm{N}$-unprotected $55^{\prime}-O$ DMTr-deoxyribonucleosides with methyl ( $N, N^{\prime}$-tetraisopropyl)phosphorodiamidite in the presence of diisopropylammonium $1 \mathrm{H}$ tetrazolide (Fig. 3.10.6, method B; Gryaznov and Letsinger, 1991, 1992). The $\mathrm{N}$-unprotected deoxyribonucleoside $3^{\prime}$ - $\left(O\right.$-cyanoethyl- $N, N^{\prime}$ tetraisopropylphosphoramidite) building blocks were also synthesized by reaction of 5'-O-DMTr-deoxyribonucleosides with $(i-\mathrm{Pr})_{2} \mathrm{NP}(\mathrm{Cl}) \mathrm{OCH}_{2} \mathrm{CH}_{2} \mathrm{CN}$ in tetrahydrofuran in the presence of diisopropylethylamine (method A; Hayakawa and Kataoka, 1998). As far as the solubility of these synthetic units is concerned, the guanosine $3^{\prime}$-( $O$-cyanoethyl)phosphoramidite is not completely soluble in acetonitrile, which is the most suitable solvent for DNA synthesizers because of its low viscosity. It is necessary to take this poor solubility into account when using an automated DNA synthesis approach, as it may cause clogging of the tubing.

\section{Oligodeoxyribonucleotide Synthesis Using the Phosphoramidite Approach}

The first report of a solid-phase DNA synthesis without base protection was made by Ogilvie and Nemer (1981), who synthesized a short oligoribonucleotide, UGCA, in $80 \%$ yield using a polymer-bound non-N-acylated adenosine derivative and the phosphite triester approach.

Later, Gryaznov and Letsinger $(1991,1992)$ reported a general method for the synthesis
Synthesis of Unmodified Oligonucleotides

3.10.5 


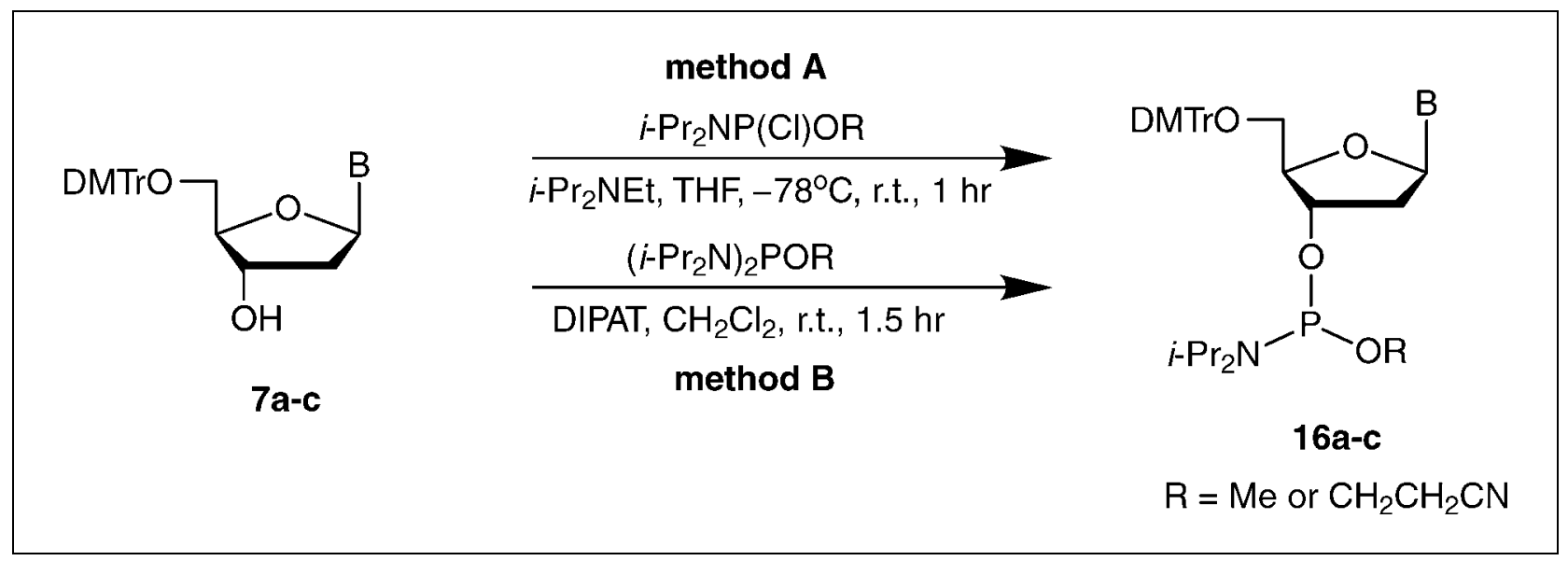

Figure 3.10.6 Synthesis of N-unprotected deoxyribonucleoside 3'-O-phosphoramidite building blocks. DIPAT, diisopropylammonium $1 \mathrm{H}$-tetrazolide; r.t., room temperature; THF, tetrahydrofuran.

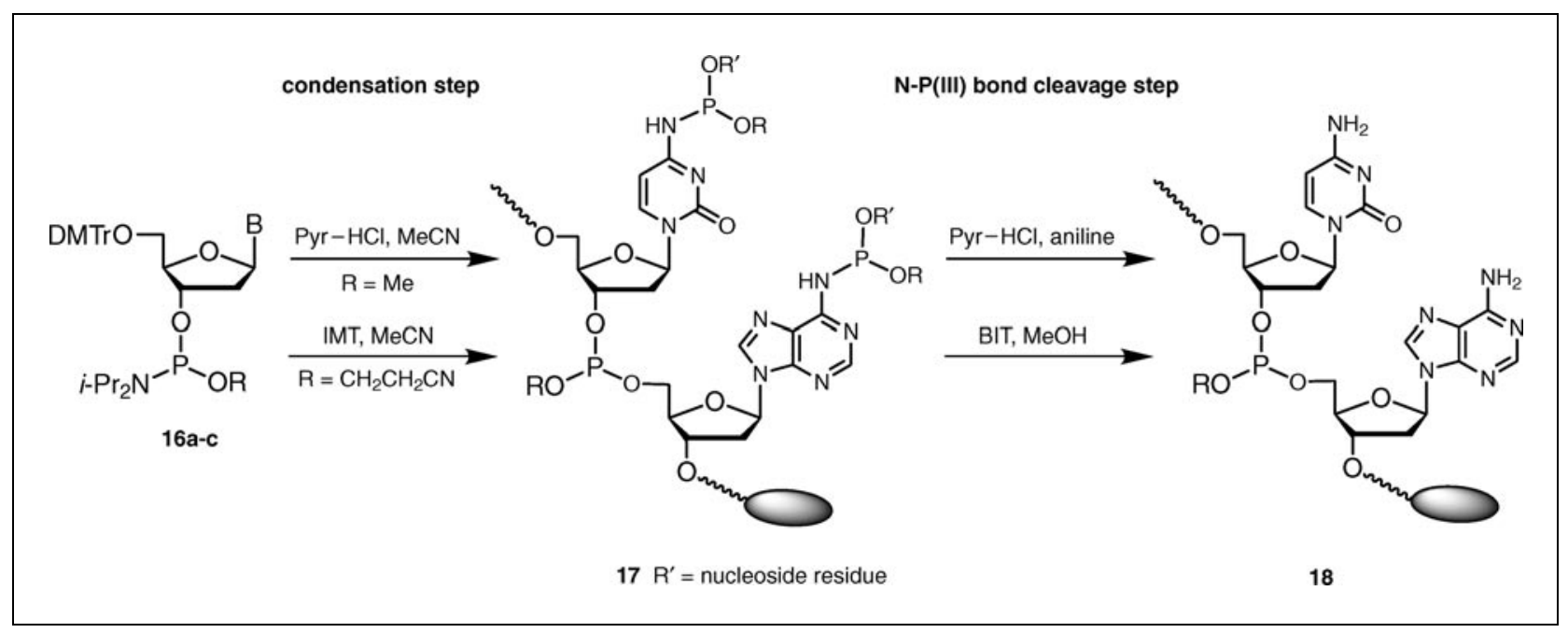

Figure 3.10.7 Synthesis of oligodeoxyribonucleotides without base protection using the phosphoramidite approach, and postcondensation treatment for N-P bond cleavage of branched chains resulting from concomitant side reactions on $\mathrm{dA}$ and $\mathrm{dC}$ bases. BIT, benzimidazolium triflate; IMT, imidazolium triflate; $\mathrm{Pyr}-\mathrm{HCl}$, pyridinium hydrochloride.

DNA Synthesis

Without Base

Protection

\subsection{6}

of oligodeoxyribonucleotides using pyridinium hydrochloride as the activator and their original syringe method (Tanaka and Letsinger, 1982; Fig. 3.10.7). With this approach, they succeeded in synthesizing 20mers. Because they observed serious modifications of the $\mathrm{dA}$ and $\mathrm{dC}$ bases, the modified sites were reconverted to free amino groups after each condensation by treatment with aniline in the presence of pyridinium hydrochloride. When internucleotide bonds are formed using the phosphoramidite approach, it is noteworthy that the guanine moiety is not modified with activated phosphoramide species (Gryaznov and Letsinger, 1991, 1992). This is in sharp contrast to the fact that significant 6-O-phosphorylation of $\mathrm{dG}$ residues has been observed when the phosphotriester approach was employed (Sekine et al., 1982).
A newer phosphoramidite approach was reported using imidazolium triflate (IMT) as a new activator and using a somewhat swelled Tentagel as the resin (Hayakawa and Kataoka, 1998; Hayakawa et al., 2001). In this approach, a more powerful activator, benzimidazolium triflate (BIT; Hayakawa et al., 1996; Hayakawa, 2001), was used in methanol as a nucleophile to eliminate $5^{\prime}$ $O$-DMTr-deoxyribonucleoside $\quad 3$-phosphityl residues from unavoidably modified base sites. By this method, 32-mer, 60-mer, and two 21-mer oligonucleotides were synthesized as the major products using a DNA synthesizer. The reproducibility of this approach has not been confirmed, however, as no applications of this method have appeared to date. As the solvent used for this synthesis was acetonitrile, it seems to be somewhat difficult to 


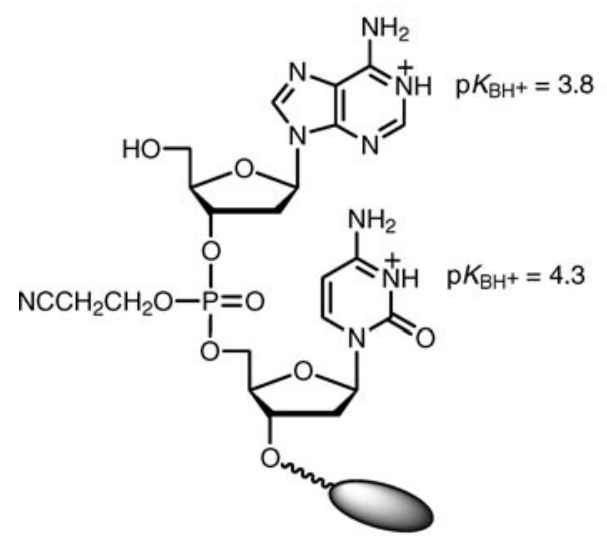

19
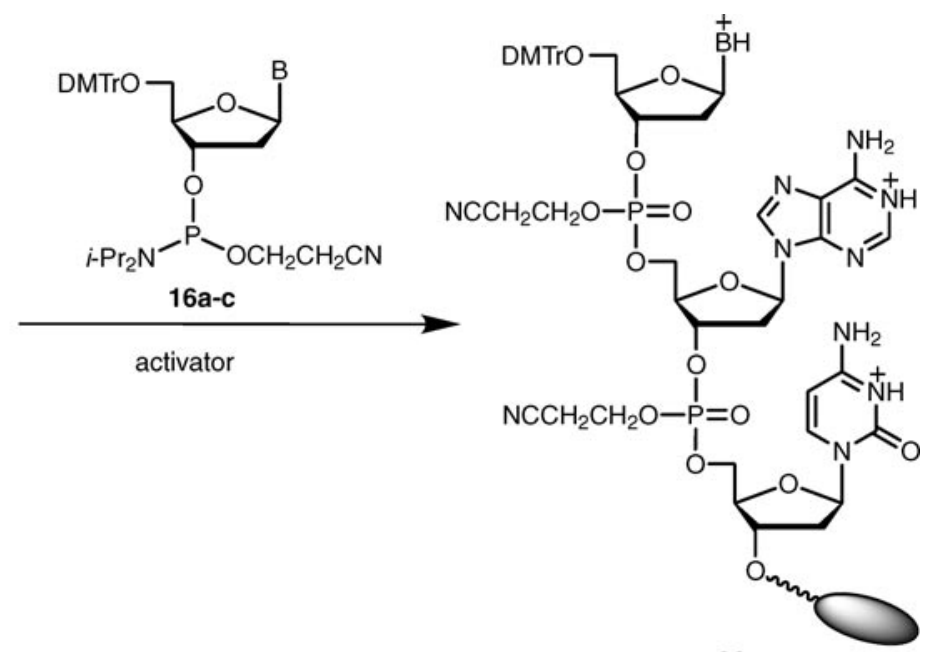

20

Figure 3.10.8 Outline of the proton-block method using the activator 5-nitrobenzimidazolium triflate (NBT).

completely dissolve the guanosine building block. On the other hand, it has recently been reported that the $\mathrm{BIT} / \mathrm{MeOH}$ treatment causes serious internucleotide bond fission $(\sim 50 \%$; Sekine et al., 2003) when highly cross-linked polystyrene (HCP; McCollum and Andrus, 1991) or controlled-pore glass (CPG; Köster et al., 1983) were employed as the resin in place of Tentagel.

Another new strategy for oligodeoxyribonucleotide synthesis without base protection takes a completely different approach. It is called the "proton-block" method, because the simple proton is used for protection of base moieties (Fig. 3.10.8; Sekine et al., 2003). This strategy was developed based on the principle of acid-base reactions. It is well known that once amino functions are protonated they lose nucleophilicity because of the formation of inert ammonium salts. Adamiak's successful 5'-O-monomethoxytritylation of ribonucleosides (Adamiak, 1981; see Synthesis of Common Starting Nucleosides) is the only precedent that utilizes this principle in nucleic acid chemistry. Based on this principle, a new activator, 5-nitrobenzimidazolium triflate (NBT), was synthesized. This new promoter has a $\mathrm{p} K_{\mathrm{a}}$ value of 2.76 and thus enables sufficient protonation of cytosine and adenine bases, which have $\mathrm{p} K_{\mathrm{BH}^{+}}$values of 4.3 and 3.8, respectively (Hall, 1971).

To date, such uses of a more acidic species as the promoter for the phosphoramidite approach have not been reported. It has been reported that 5-(4-nitrophenyl)-1H-tetrazole (Froehler and Matteucci, 1983b) is so acidic $\left(\mathrm{p} K_{\mathrm{a}}=3.7\right)$ that it causes serious elimina- tion of the DMTr group. When NBT was used in acetonitrile for the solid-phase synthesis of $\mathrm{d}[\mathrm{ApT}], 3 \%$ of the product was obtained as $\mathrm{d}[\mathrm{ApApT}]$. This side reaction could be significantly suppressed, however, by using THF as the solvent. This solvent effect can be explained by the difference in basicity between acetonitrile and THF, which have $\mathrm{p} K_{\mathrm{BH}^{+}}$values of -10 and -2 , respectively (see Internet Resource). The 5'-DMTr ether linkage (DMTr$\left.\mathrm{O}-\mathrm{CH}_{2}-\right)$ was estimated to have a $\mathrm{p} K_{\mathrm{BH}^{+}}$value that is between those of acetonitrile and THF, and probably nearer to THF, so that NBT cannot protonate the DMTr ether linkage in the presence of excess amounts of the more basic THF. It is important to choose the correct solvent in this strategy. The oligos d[CCCCCT] and d[AAAAAT] were synthesized without base protection and without postcondensation treatment with $\mathrm{P}-\mathrm{N}$ bond-cleaving reagents. In the synthesis of d[CAGTCAGTCAGT], a mixed solvent of 9:1 (v/v) acetonitrile/Nmethylpyrrolidone (NMP) was used to avoid the competitive elimination of the DMTr group during the condensation. NMP has a $\mathrm{p} K_{\mathrm{BH}^{+}}$ value of -0.71 , so that the excess promoter protonates this solvent predominantly over the 5 -etheral oxygen. Consequently, the 12-mer was obtained in $19 \%$ overall yield. The superiority of this strategy is evidenced by the fact that, when IMT was used as the promoter without the postcondensation treatment with BIT-MeOH, an extremely complicated HPLC profile was obtained (Sekine et al., 2003).

Finally, a new strategy called the HOBT method has been developed (Fig. 3.10.9;
Synthesis of Unmodified Oligonucleotides

3.10.7 


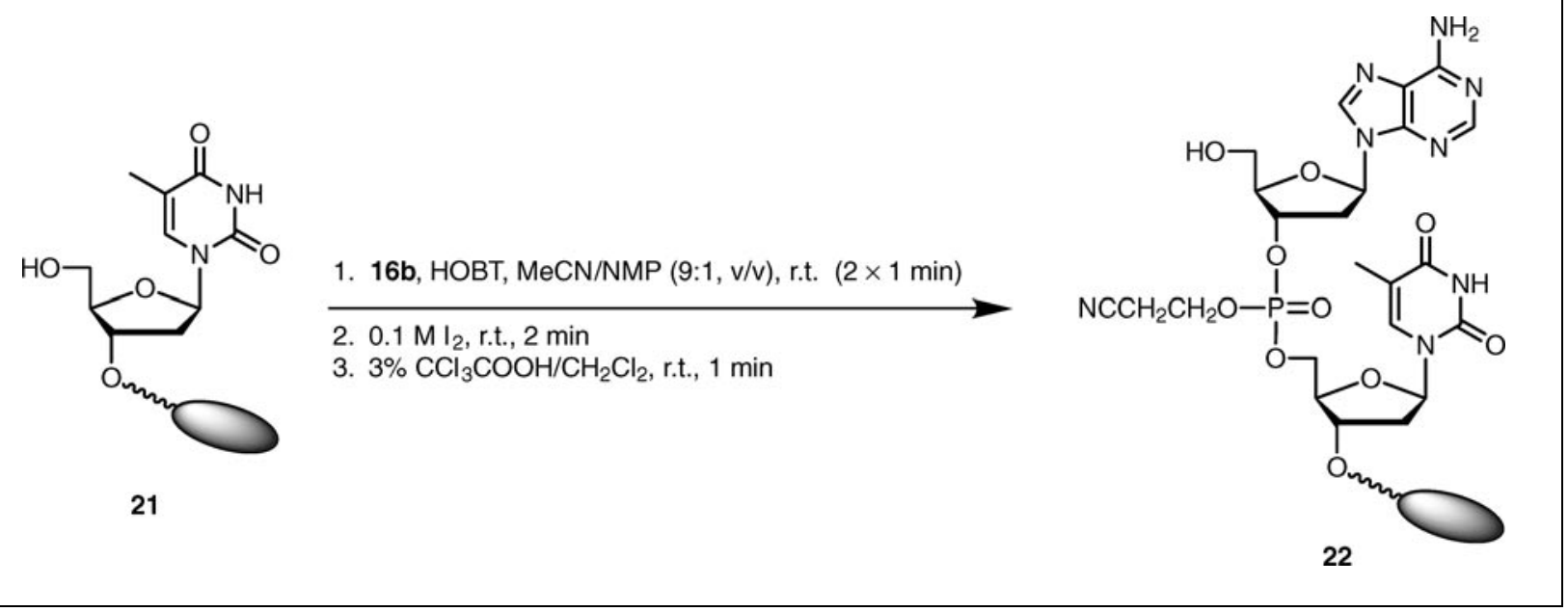

Figure 3.10.9 The HOBT method for oligodeoxyribonucleotide synthesis without base protection and without postcondensation treatment. HOBT, 1-hydroxybenzotriazole; NMP, $N$-methylpyrrolidone; r.t., room temperature.

DNA Synthesis

Without Base

Protection

\subsection{0 .8}

Ohkubo et al., 2002). 1-Hydroxy-benzotriazole (HOBT) was previously used as the promoter in the phosphoramidite approach by van Boom (Claesen et al., 1984). However, because of the poor solubility of this reagent in acetonitrile, which is widely used for automated DNA synthesizers, syntheses using HOBT had not appeared until this HOBT strategy was reported. Based on the mechanism of the $H$-phosphonate approach without base protection, HOBT was the reagent of choice for the purpose. Because the intermediate of a previous $H$-phosphonate approach without base protection was thought to be a tervalent phosphorus species (Wada et al., 1997; UNIT 3.4), it was believed that this kind of tervalent phosphorus species would be essential for O-selective internucleotide bond formation, and suitable reagents that can convert phosphoramidite derivatives to tervalent phosphite triester intermediates were studied. Among the reagents tested, HOBT was found to be the best reagent for O-selective internucleotide bond formation. Because HOBT $\left(\mathrm{p} K_{\mathrm{a}}=5.3\right)$ is more basic than $1 H$-tetrazole $\left(\mathrm{p} K_{\mathrm{a}}=4.8\right)$, there is no risk of elimination of the DMTr group during condensation, unlike the proton-block method. The only drawback of this reagent is its inherent insolubility in acetonitrile, but this was overcome by using a mixed solvent of acetonitrile and NMP. Moreover, the insolubility of the $\mathrm{dG}$ phosphoramidite, another common problem in the $\mathrm{N}$ unprotected strategy, was also overcome by the use of the mixed acetonitrile/NMP solvent, in which the $\mathrm{dG}$ building block is easily soluble. With the help of these improvements,
d[CAGTCAGTCAGT] was synthesized as the major product in high yield. The $\mathrm{O}$-selectivity in the synthesis of dimers and trimers exceeded $99.8 \%$, a most excellent result. This approach enabled the synthesis of up to 20 -mer oligodeoxyribonucleotides. The coupling efficiency decreased to $\sim 98 \%$, however, when the $\mathrm{dG}$ monomer was used. If this problem could be solved, the HOBT method would be more realistic and practical.

\section{SOLID-PHASE SYNTHESIS USING THE $H$-PHOSPHONATE APPROACH}

\section{Synthesis of Deoxyribonucleoside 3'-Phosphonate Building Blocks}

Synthesis of $\quad 5^{\prime}$-O-DMTr-deoxyribonucleoside $3^{\prime}-H$-phosphonates was reported by several research groups. Levin et al. (1991) reported synthesis using salicyl chlorophosphite (Marugg et al., 1986; Ven'yaminova et al., 1988) as the phosphitylating reagent (Fig. 3.10.10, method B). Phosphonylation of $N$-dimethylaminomethylene5'-O-DMTr-deoxyribonucleosides with tris(triazolyl)phosphine (method A) gave the 3'-phosphonylated products as 1,8diazabicyclo-[5,4,0]undec-7-ene (DBU) salts (Kung and Jones, 1992). In the case of $\mathrm{dC}$, the N-unprotected product was obtained directly, as the amidine group was completely lost during silica gel column chromatography. In the case of $\mathrm{dA}$ and $\mathrm{dG}$, however, concomitant elimination of the amidine group occurred, giving a mixture of $\mathrm{N}$-protected and $\mathrm{N}$-unprotected products. 


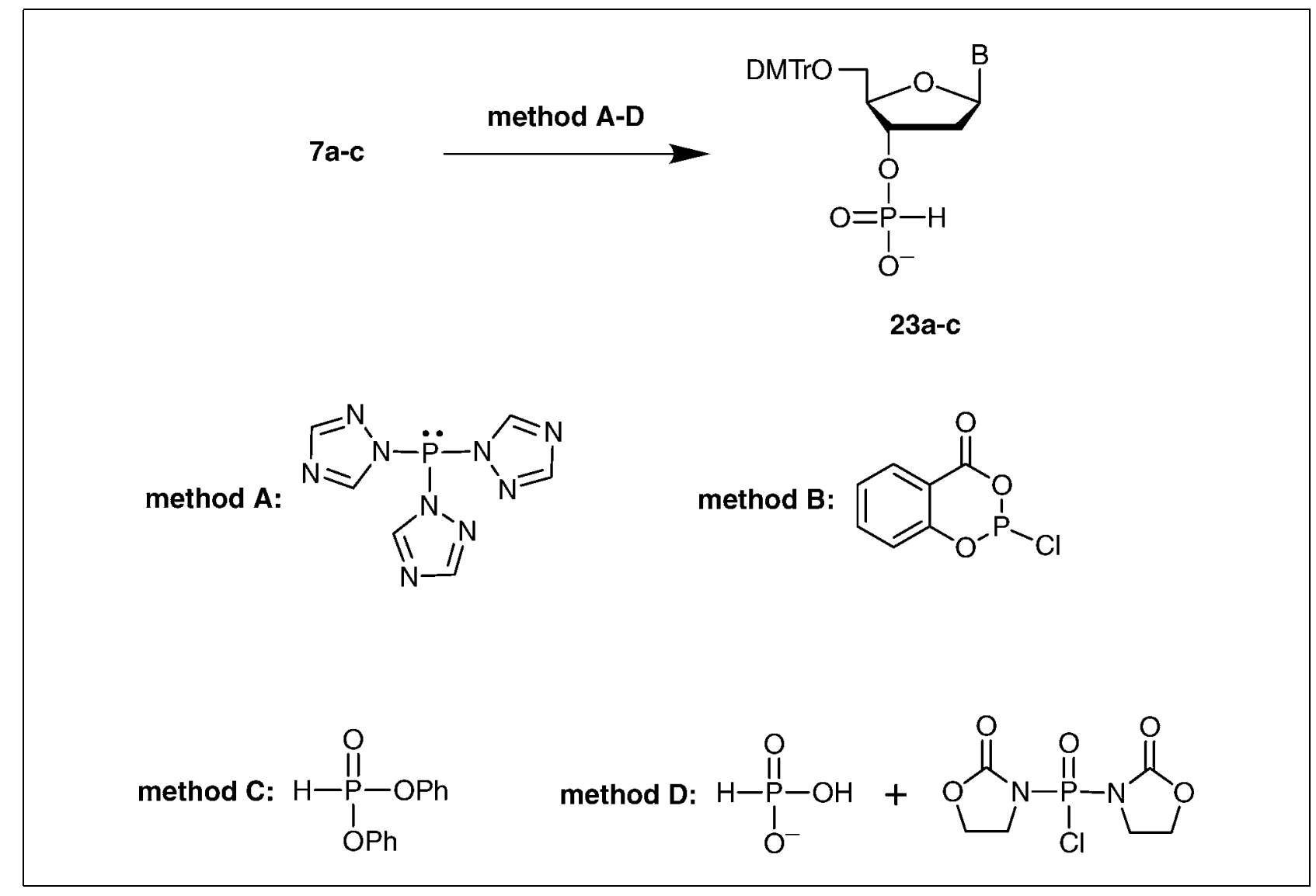

Figure 3.10.10 Synthesis of N-unprotected deoxyribonucleoside 3'-O-phosphonate building blocks for oligonucleotide synthesis using the $\mathrm{H}$-phosphonate approach.

Therefore, pretreatment of the crude products with ammonia before chromatography is necessary. Wada and Sekine reported the selective $3^{\prime}-\mathrm{O}$-phosphonylation of $5^{\prime}-\mathrm{O}$ DMTr-deoxyribonucleosides with excess diphenyl phosphonate or with phosphonic acid in the presence of bis(2-oxo-3-oxazolidinyl)phosphinic chloride (methods $\mathrm{C}$ and $\mathrm{D}$, respectively; Wada et al., 1997). The use of method $\mathrm{C}$ gave somewhat better yields of the $3^{\prime}$ - $O$-phosphonylated products as DBU salts compared to method D ( $88 \%$ to $94 \%$ versus $78 \%$ to $87 \%$, respectively).

\section{Oligodeoxyribonucleotide Synthesis Using the $\boldsymbol{H}$-Phosphonate Approach}

Levin et al. (1991) first reported the synthesis of oligodeoxyribonucleotides by the $H$-phosphonate method using $\mathrm{N}$-unprotected 5'-O-DMTr-deoxyribonucleoside 3' -phosphonates. They synthesized d[TATTTGGCT], but no details concerning the reaction conditions were described. Kung and Jones (1992) reported the synthesis of DMTr-d[TCAGT] using the $H$-phosphonate approach with pivaloyl chloride or adamantyl chloride as the coupling reagent (Fig. 3.10.11). In this synthesis, it was found that pivaloyl chloride reacted with base residues. Although the pivaloyl groups were removed by standard ammonia treatment, the necessity for such ammonia treatment eliminates one of the advantages to not using amino-protecting groups.

In 1997, Wada and Sekine also reported the use of the $H$-phosphonate approach without base-protecting groups (Wada et al., 1997; Fig. 3.10.12). In their approach, a phosphoniumtype condensing reagent, BOMP, was developed and shown to be very effective for selective internucleotide bond formation. The synthesis of d[CAGTCAGTCAGT] was accomplished with an overall isolated yield of $19 \%$. Of particular interest, a plausible explanation as to why the selective O-phosphorylation occurred was also reported. The detailed molecular orbital (MO) calculations of possible intermediates suggest that two sets of HOMO-LUMO (highest and lowest molecular orbital) interactions between an activated $H_{-}$ phosphonate species and the $5^{\prime}$-terminal $\mathrm{HO}$ function are involved. In the reaction of the
Synthesis of Unmodified Oligonucleotides

3.10.9 


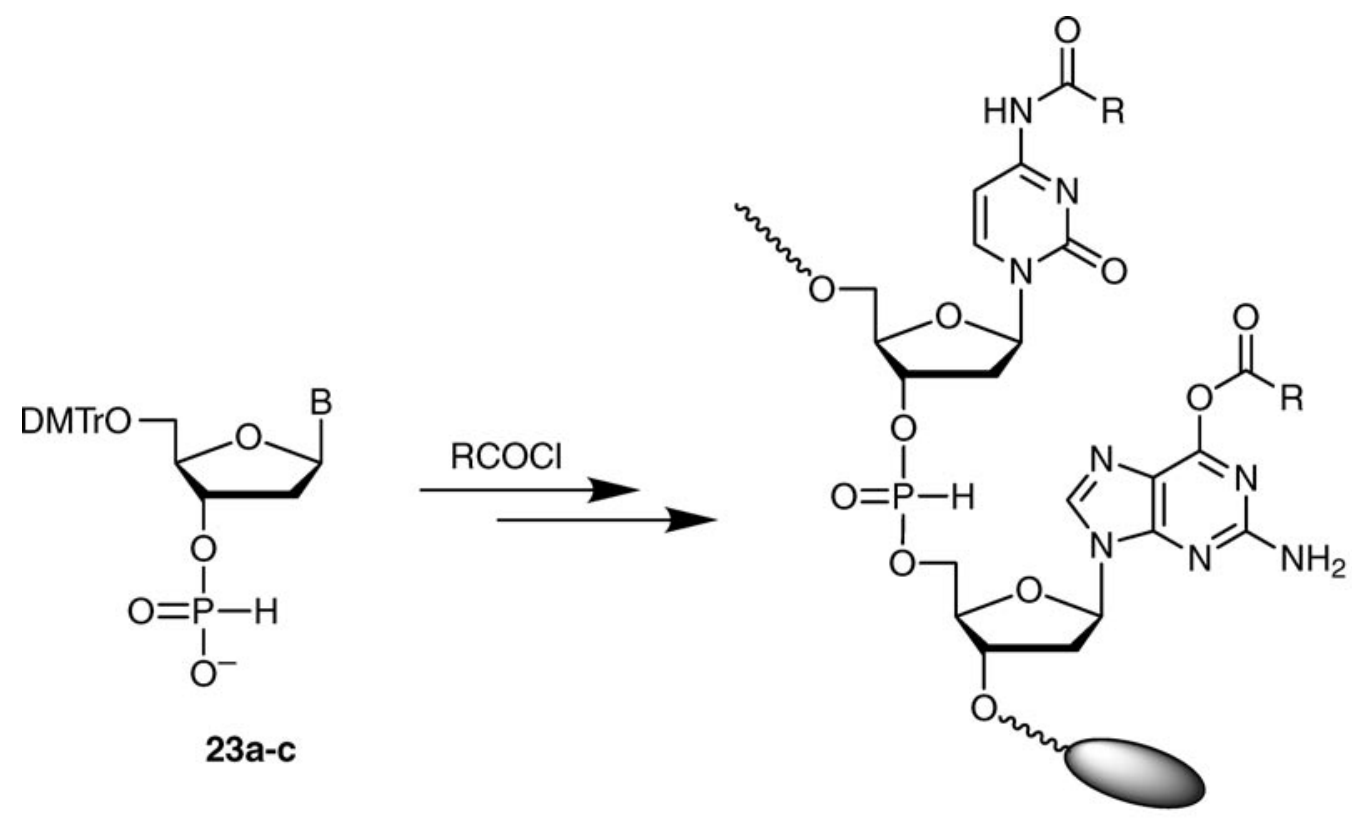

$24 \mathrm{R}=t$-Bu or 1-adamantyl

Figure 3.10.11 Use of pivaloyl chloride (trimethylacetyl chloride, $\mathrm{R}=t$-Bu) for synthesis of oligodeoxyribonucleotides by the $H$-phosphonate approach without base protection.

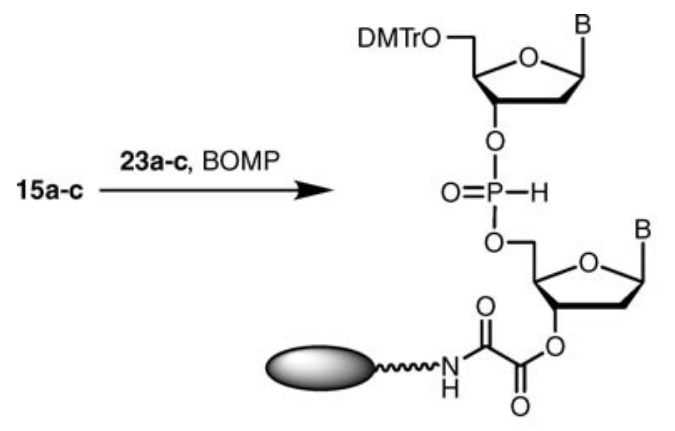

25

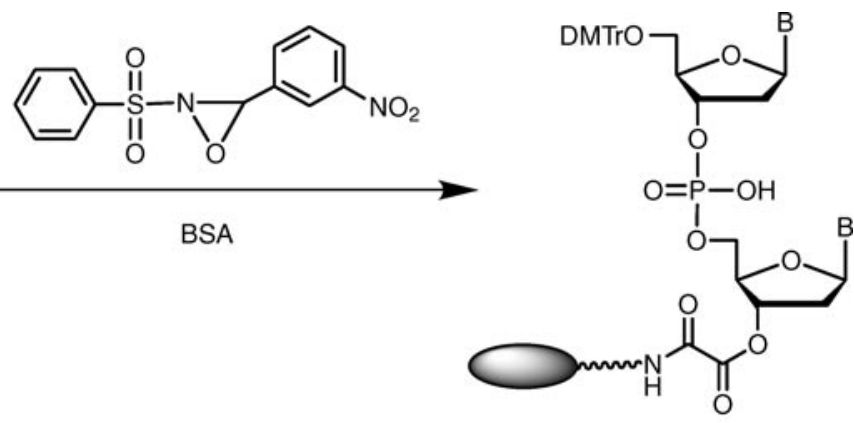

26

Figure 3.10.12 Use of phosphonium-type condensing reagents for synthesis of oligodeoxyribonucleotides by the $H$ phosphonate approach without base protection. B is the unprotected nucleobase. BOMP, (2-benzotriazol-1-yloxy)-1,3dimethyl-2-pyrrolidin-1-yl-1,3,2-diazaphospholidinium hexafluorophosphate; BSA, N,O-bis(trimethylsilyl)acetamide; DMTr$\mathrm{Cl}, 4,4^{\prime}$-dimethoxytrityl chloride.

DNA Synthesis

Without Base

Protection

\subsubsection{0}

activated species with amino functions of the nucleobases, the HOMO orbital on the hydrogen atom of the $\mathrm{HO}$ group is lacking, so that only a weaker interaction between the nitrogen atom and the phosphorus atom of the activated species is available. Later, it was reported that this strategy was accompanied by a serious side reaction that caused elimination of one nucleotide block during the condensation, resulting in the formation of significant amounts of (n-1)-mers (Wada et al., 1999).

\section{ADVANTAGES AND PROSPECTS OF THE N-UNPROTECTED APPROACH}

\section{Stability of N-Unprotected \\ Deoxyribonucleoside Derivatives}

The stability of the glycosidic bond of $\mathrm{N}$ unprotected deoxyribonucleoside derivatives is important. Several research groups have reported the kinetic data of $\mathrm{N}$-protected and $\mathrm{N}$-unprotected deoxyadenosine derivatives 
(Butkus et al., 1983; Septak, 1996; Krotz et al., 2003). Froehler and Matteucci (1983a) reported that $\mathrm{N}$-unprotected deoxyadenosine is more resistant to acids than is $\mathrm{N}$-benzoyldeoxyadenosine. Specifically, $\mathrm{N}$ benzoyldeoxyadenosine has a $T_{1 / 2}$ of $4 \mathrm{hr}$ in $80 \%$ acetic acid at $25^{\circ} \mathrm{C}$, whereas $\mathrm{N}$ unprotected deoxyadenosine has a $T_{1 / 2}$ of $>5$ days. The stability of the glycosidic bond of deoxyadenosine is similar to that of 6$N$-diisopropylformamidinedeoxyadenosine. It was also reported that unprotected deoxyguanosine is somewhat more unstable than deoxyadenosine under acidic conditions (Venner, 1964, 1966). This is in reverse order of the same series of $\mathrm{N}$-acylated purine deoxyribonucleosides. In the current phosphoramidite approach using N-protected deoxyribonucleosides, it is important to balance the contradictory goals of obtaining maximum detritylation with minimum depurination at the final stage (Septak, 1996; Krotz et al., 2003).

\section{Prospects of N-Unprotected Approach}

One promising advantage of the Nunprotected phosphoramidite approach is to make it possible to synthesize oligodeoxyribonucleotides directly on a resin or even on microchips or microarrays. The straightforward synthesis of DNA fragments on DNA microchips or microarrays will be realized in the near future. For this purpose, O-selectivity at the present level of internucleotide bond formation can be sufficiently utilized without difficulty. In gene diagnosis, success relies on the ability of a complementary sequence to bind to the patients' target sequence on the DNA chip and not other sequences. In this respect, achievement of $99.8 \%$ to $99.9 \%$ O-selectivity (Ohkubo et al., 2002) in the chemical synthesis of DNA fragments means the high presence of the correct sequence relative to incorrect sequences. Because O-selectivity is nearly perfect in the HOBT method, the ratio of the correct sequence to each failure sequence is highly dependent on the efficiency of condensation at each cycle. As no capping treatment is carried out, the correct sequence is unavoidably contaminated with failure sequences lacking one nucleotide unit. If the coupling efficiency is $99 \%$, then $1 \%$ failure sequences are obtained at each coupling. The ratio of the correct sequence to each shorter sequence is calculated to range from $89.5: 1$ to $99: 1$. Therefore, rather high base recognition can be expected. It is apparent that, with increasing chain length of the DNA fragments, formation of N-branched DNA molecules increases exponentially. Therefore, the $\mathrm{N}$-unprotected strategy has a certain limitation in this respect, although it seems that a 20-mer synthesis is at least achievable without significant difficulty.

In addition to these advantages, there is a possibility that because the HOBT method can provide oligodeoxyribonucleotides with phosphotriester linkages directly on DNA microchips or microarrays, O-protected oligodeoxyribonucleotides can be used as neutral DNA probes that can bind to target DNA or RNA fragments of patients for gene diagnosis. This possibility should be tested in the near future. Several kinds of O-alkylated oligodeoxyribonucleotide derivatives maintain hybridization properties when bound to complementary oligodeoxyribonucleotides (Yamana et al., 1991; Iyer et al., 1995, 1996). For gene diagnosis using DNA microchips or microarrays, unlike gene therapy, there is no need to consider the reactivity of phosphotriester linkages as potential alkylating reagents toward target nucleic acids or other molecules such as proteins and lipids.

In previous approaches to the synthesis of DNA oligomers containing base-labile functional groups, various $\mathrm{N}$-protecting groups have been developed that are removable under neutral conditions (Dreef-Tromp et al., 1991; Iyer et al., 1995; Alvarez et al., 1999; Spinelli et al., 2002). The N-unblocked strategy described here would be useful as a more straightforward approach to base-labile modified DNA derivatives. For example, the $H$ phosphonate approach without base protection was successfully applied to the synthesis of oligodeoxyribonucleotides having base-labile $\mathrm{N}$-acetyldeoxycytidine residues, which proved to form a Watson-Crick base pair with guanine more effectively than the unmodified base (Wada et al., 1998a). Several papers related to this application have also appeared (Wada et al., 2001a; Kobori et al., 2002b).

Because the phosphoramidite approach uses tervalent phosphorous compounds as the monomer units, it is impossible to synthesize oligodeoxyribonucleotides having functions that react with them or the activated intermediates. For example, the azido group is a typical functional group that reacts with phosphoramidites or phosphites to undergo the Staudinger reaction. In such a case, the $H$ phosphonate approach without base protection is useful. An oligodeoxyribonucleotide derivative having 2-azidodeoxyadenosine was successfully synthesized by the BOMP strategy
Synthesis of Unmodified Oligonucleotides

3.10.11 
(Wada et al., 2001b). On the other hand, the $H$-phosphonate method was used not only for isolation of base-labile $H$-phosphonate DNA oligomers (Wada et al., 1999) but also for the synthesis of hydroxymethylphosphonate DNA oligomers (Wada and Sekine, 1995).

In the near future, the aforementioned $\mathrm{N}$-unprotected strategies could be used for the synthesis of other targets, such as oligodeoxyribonucleotides having ester or aldehyde groups, that cannot be obtained directly by the use of modified deoxyribonucleoside $3^{\prime}$-phosphoramidites or $3^{\prime}$-phosphonates. For this purpose, suitable phosphate-protecting groups as well as linkers that are removable under neutral conditions should be developed. Some strategies described in recent papers (Kobori et al., 2002a; Ushioda et al., 2002) would be useful for further studies in this direction.

\section{Literature Cited}

Adamiak, R.W. and Stawinski, J. 1977. A highly effective route to $N, N^{\prime}$-disubstituted ureas under mild conditions. An application to the synthesis of tRNA anticodon loop fragments containing ureidonucleosides. Tetrahedron Lett. 18:19351936.

Adamiak, R.W., Biala, E., Grzeskowiak, K., Kierzek, R., Kraszewski, A., Markiewicz, W.T., Okupniak, J., Stawinski, J., and Wiewiorowski, M. 1978. The chemical synthesis of the anticodon loop of an eukaryotic initiator tRNA containing the hypermodified nucleoside $N^{6}-/ N$ threonylcarbonyl/-adenosine $/ \mathrm{t}^{6} \mathrm{~A} /$. Nucl. Acids Res. 5:1889-1905.

Alvarez, K., Vasseur, J.-J., and Imbach, J.-L. 1999. Use of photolabile amino-protecting groups in the synthesis of base-sensitive DNA SATE-phosphotriesters. Nucleosides $\mathrm{Nu}$ cleotides 18:1435-1436.

Baddiley, J. and Todd, A.R. 1947. Nucleotides. I. Muscle adenylic acid and adenosine diphosphate. J. Chem. Soc. 648-651.

Beaucage, S.L. and Iyer, R.P. 1992. Advances in the synthesis of oligonucleotides by the phosphoramidite approach. Tetrahedron 48:2223-2311.

Boal, J.H., Wilk, A., Harindranath, N., Max, E.E., Kempe, T., and Beaucage, S.L. 1996. Cleavage of oligodeoxyribonucleotides from controlledpore glass supports and their rapid deprotection by gaseous amines. Nucl. Acids Res. 24:31153117.

Butkus, V., Kayushin, A.L., Berlin, Y.A., Kolosov, M.N., and Smirnov, I.V. 1983. Cleavage of 5'-Oprotecting trityl groups in oligodeoxynucleotide synthesis. Effect of substrate structure and reaction conditions on detritylation and depurination rates. Bioorg. Khim. 9:1518-1530.

DNA Synthesis Without Base Protection 3.10.12

Caruthers, M.H. 1991. Chemical synthesis of DNA and DNA analogues. Acc. Chem. Res. 24:278284.
Claesen, C., Tesser, G.I., Dreef, C.E., Marugg, J.E., van der Marel, G.A., and van Boom, J.H. 1984. Use of 2-methylsulfonylethyl as a phosphorus protecting group in oligonucleotide synthesis via a phosphite triester approach. Tetrahedron Lett. 25:1307-1310.

Dreef-Tromp, C.M., Van Dam, E.M.A., van den Elst, H., van den Boogaart, J.E., van der Marel, G.A., and van Boom, J.H. 1991. Solid-phase synthesis of RNA via a silyl-protecting-group strategy. Recl. Trav. Chim. Pays Bas 110:378383.

Finnan, J.L., Varshney, A., and Letsinger, R.L. 1980. Developments in the phosphite-triester method of synthesis of oligonucleotides. Nucl. Acids Res. Symp. Ser. 7:133-145.

Fourrey, J.-L. and Varenne, J. 1985. Preparation and phosphorylation reactivity of $\mathrm{N}$-nonacylated nucleoside phosphoramidites. Tetrahedron Lett. 26:2663-2666.

Froehler, B.C. and Matteucci, M.D. 1983a. Dialkylformamidines: Depurination resistant $N^{6}$ protecting group for deoxyadenosine. Nucl. Acids Res. 11:8031-8036.

Froehler, B.C. and Matteucci, M.D. 1983b. Substituted 5-phenyltetrazoles: Improved activators of deoxynucleoside phosphoramidites in deoxyoligonucleotide synthesis. Tetrahedron Lett. 24:3171-3174.

Gryaznov, S.M. and Letsinger, R.L. 1991. Synthesis of oligonucleotides via monomers with unprotected bases. J. Am. Chem. Soc. 113:5876-5877.

Gryaznov, S.M. and Letsinger, R.L. 1992. Selective O-phosphitylation with nucleoside phosphoramidite reagents. Nucl. Acids Res. 20:18791882.

Hall, R.H. 1971. The Modified Nucleosides in Nucleic Acids. Columbia University Press, New York.

Hata, T. and Kurihara, T. 1973. Preparation of intermediates in the synthesis of polynucleotides. II. $N^{4}$-Benzoylation of deoxycytidylic and cytidylic acids by 2-chloromethyl-4-nitrophenyl benzoate. Chem. Lett. 8:859-862.

Hayakawa, Y. 2001. Toward an ideal synthesis of oligonucleotides: Development of a novel phosphoramidite method with high capability. Bull. Chem. Soc. Jpn. 74:1547-1565.

Hayakawa, Y. and Kataoka, M. 1998. Facile synthesis of oligodeoxyribonucleotides via the phosphoramidite method without nucleoside base protection. J. Am. Chem. Soc. 120:1239512401.

Hayakawa, Y., Aso, Y., Uchiyama, M., and Noyori, R. 1983a. Facile nucleoside phosphorylation via hydroxyl activation. Tetrahedron Lett. 24:11651168.

Hayakawa, Y., Aso, Y., Uchiyama, M., and Noyori, R. 1983b. Chemoselective phosphorylation of $\mathrm{N}$-unprotected nucleosides via aluminum alkoxides. Tetrahedron Lett. 24:5641-5644.

Hayakawa, Y., Uchiyama, M., and Noyori, R. 1984. A convenient method for the formation of 
internucleotide linkage. Tetrahedron Lett. 25:4003-4006.

Hayakawa, Y., Uchiyama, M., Nobori, T., and Noyori, R. 1985. A convenient synthesis of $2^{\prime}-5^{\prime}-$ linked oligoribonucleotides. Tetrahedron Lett. 26:761-764.

Hayakawa, Y., Nobori, T., Noyori, R., and Imai, J. 1987. Synthesis of $2^{\prime}-5^{\prime}, 3^{\prime}-5^{\prime}$ linked triadenylates. Tetrahedron Lett. 28:2623-2626.

Hayakawa, Y., Kataoka, M., and Noyori, R. 1996. Benzimidazolium triflate as an efficient promoter for nucleotide synthesis via the phosphoramidite method. J. Org. Chem. 61:7996-7997.

Hayakawa, Y., Kawai, R., and Kataoka, M. 2001. Nucleotide synthesis via methods without nucleoside-base protection. Eur. J. Pharm. Sci. 13:5-16.

Ikemoto, T., Haze, A., Hatano, H., Kitamoto, Y., Ishida, M., and Nara, K. 1995. Phosphorylation of nucleosides with phosphorus oxychloride in trialkyl phosphate. Chem. Pharm. Bull. 43:210215.

Ishido, R. 1989. Protection of 5'-hydroxy groups of cytidine derivatives. Jpn. Kokai Tokkyo Koho Jp Pat. 01308294; Chem. Abstr. 1990. 112:700.

Iyer, R.P., Yu, D., Ho, N.-H., Devlin, T., and Agrawal, S. 1995. $O$ - and $S$-Methyl phosphotriester oligonucleotides: Facile synthesis using $\mathrm{N}$-pent-4-enoyl nucleoside phosphoramidites. $J$. Org. Chem. 60:8132-8133.

Iyer, R.P., Yu, D., Devlin, T., Ho, N.-H., Johnson, S., and Agrawal, S. 1996. Synthesis, biophysical properties, and stability studies of mixed backbone oligonucleotides containing novel non-ionic linkages. Nucleosides $\mathrm{Nu}$ cleotides 16:1491-1495.

Kataoka, M. and Hayakawa, Y. 1999. A convenient method for the synthesis of $\mathrm{N}$-free $5^{\prime}-O$ ( $p, p^{\prime}$-dimethoxytrityl)-2'-deoxyribonucleosides via $5^{\prime}-O$-selective tritylation of the parent substances. J. Org. Chem. 64:6087-6089.

Kobori, A., Miyata, K., Ushioda, M., Seio, K., and Sekine, M. 2002a. A new silyl ether-type linker useful for the automated synthesis of oligonucleotides having base-labile protective groups. Chem. Lett. 31:16-17.

Kobori, A., Miyata, K., Ushioda, M., Seio, K., and Sekine, M. 2002b. A new method for the synthesis of oligodeoxyribonucleotides containing 4$\mathrm{N}$-alkoxycarbonyldeoxycytidine derivatives and their hybridization properties. J. Org. Chem. 67:476-485.

Koole, L.H., Buck, H.M., Kanters, J.A., and Schouten, A. 1987. Molecular conformation of $2^{\prime}$-deoxy-3',5'-di- $O$-acetyladenosine. Crystal structure and high resolution proton nuclear magnetic resonance investigations. Can. J. Chem. 65:326-331.

Köster, H., Stumpe, A., and Wolter, A. 1983. Polymer support oligonucleotide synthesis. 13. Rapid and efficient synthesis of oligodeoxynucleotides on porous glass support using triester approach. Tetrahedron Lett. 24:747-750.
Krotz, A.H., McElroy, B., Scozzari, A.N. Cole, D.L., and Ravikumar, V.T. 2003. Controlled detritylation of antisense oligonucleotides. Org. Process Res. Dev. 7:47-52.

Kume, A., Iwase, R., Sekine, M., and Hata, T. 1984. Cyclic diacyl groups for protection of the $N^{6}$-amino group of deoxyadenosine in oligodeoxynucleotide synthesis. Nucl. Acids Res. 12:8525-8538.

Kung, P.-P. and Jones, R.A. 1992. H-Phosphonate DNA synthesis without amino protection. Tetrahedron Lett. 33:5869-5872.

Letsinger, R.L., Finnan, J.L., Jacobs, S.A., Juodka, B.A., and Varshney, A.K. 1976. Exploration of new procedures for the synthesis of polynucleotides. In Proceedings of the International Conference on Synthesis, Structure and Chemistry of Transfer Ribonucleic Acids and Their Components, Dymaczewo, Poland, September 13-17, 1976. Institute of Organic Chemistry, Polish Academy of Sciences.

Levin, A.S., Tabatadze, E.R., and Komarova, N.I. 1991. Synthesis of oligodeoxyribonucleotides by $H$-phosphonate method using $\mathrm{N}$-unblocked synthons. Sibirskii Khim. Z. 6:142-144

Marugg, J.E., Tromp, M., Kuyl-Yeheskiely, E., van der Marel, G.A., and van Boom, J.H. 1986. A convenient and general approach to the synthesis of properly protected $d$-nucleoside $3^{\prime}$ hydrogen phosphonates via phosphite intermediates. Tetrahedron Lett. 27:2661-2664.

McCollum, C. and Andrus, A. 1991. An optimized polystyrene support for rapid, efficient oligonucleotide synthesis. Tetrahedron Lett. 32:40694072.

Michelson, M. and Todd, A.D. 1954. Nucleotides. Part XXIII. Mononucleotides derived from deoxycytidine. Note on the structure of cytidylic acids a and b. J. Chem. Soc. 34-40.

Nikolenko, L.N., Nezavibat'ko, V.N., and Tolmacheva, N.S. 1967. Selective N-benzoylation of deoxycytidine and cytidine. Khim. Prir. Soedin. 3:359.

Nishino, S., Nagato, Y., Hasegawa, Y., Yamamoto, H., Kamaike, K., and Ishido, Y. 1991. Partial protection of carbohydrate derivatives. Part 27. Efficient deanilidation of phosphoranilidates by the use of nitrites and acetic anhydride. Heteroatom. Chem. 2:187-196.

Ogilvie, K.K. 1973. The tert-butyldimethylsilyl group as a protecting group in deoxynucleosides. Can. J. Chem. 51:3799-3807.

Ogilvie, K.K. and Nemer, M. 1981. Nonaqueous oxidation of phosphites to phophates in nucleotide synthesis. Tetrahedron Lett. 22:2531-2532.

Ohkubo, A., Ezawa, Y., Seio, K., and Sekine, M. 2002. A new strategy for the synthesis of oligodeoxynucleotides in the phosphoramidite method without base protection via phosphite intermediates. Nucl. Acids Res. Suppl. 2:2930.

Okupniak, J., Adamiak R.W., and Wiewiorowski, M. 1981. New conditions for a selective
Synthesis of Unmodified Oligonucleotides

3.10.13 
introduction of trityl type protective group into adenosine and cytidine $3^{\prime}$-phosphates. Pol. J. Chem. 55:679-682.

Pearson, R.G. 1987. Recent advances in the concept of hard and soft acids and bases. J. Chem. Educ. 64:561-567.

Pearson, R.G. 1990. Hard and soft acids and basesthe evolution of a chemical concept. Coord. Chem. Rev. 100:403-425.

Schaller, H., Weimann, G., Lerch, B., and Khorana, H.G. 1963. Studies on polynucleotides. XXIV. The stepwise synthesis of specific deoxyribopolynucleotides. Protected derivatives of deoxyribonucleosides and new syntheses of deoxyribonucleoside 3'-phosphates. J. Am. Chem. Soc. 85:3821-3827.

Schulhof, J.C., Molko, D., and Teoule, R. 1987. Facile removal of new base protecting groups useful in oligonucleotide synthesis. Tetrahedron Lett. 28:51-54.

Sekine, M., Matsuzaki, J., Satoh, M., and Hata, T. 1982. Improved $3^{\prime}-O$-phosphorylation of guanosine derivatives by $O^{6}$-oxygen protection. J. $\mathrm{Org}$. Chem. 47:571-573.

Sekine, M., Masuda, N., and Hata, T. 1985. Introduction of the $4,4^{\prime}, 4^{\prime \prime}$-tris(benzoyloxy)trityl group into the exo amino groups of deoxyribonucleosides and its properties. Tetrahedron 41:5445-5453.

Sekine, M., Ohkubo, A., and Seio, K. 2003. Protonblock strategy for the synthesis of oligodeoxynucleotides without base protection, capping reaction, and P-N bond cleavage reaction. J. Org. Chem. 68:5478-5492.

Septak, M. 1996. Kinetic studies on depurination and detritylation of CPG-bound intermediates during oligonucleotide synthesis. Nucl. Acids Res. 24:3053-3058.

Shena, M. 1999. DNA Microarrays: A practical approach. Oxford University Press, London.

Spinelli, N., Meyer, A., Hayakawa, Y., Imbach, J.L., and Vasseur, J.-J. 2002. Use of allylic protecting groups for the synthesis of base-sensitive prooligonucleotides. Eur. J. Org. Chem. 4956.

Tanaka, T. and Letsinger, R.L. 1982. Syringe method for stepwise chemical synthesis of oligonucleotides. Nucl. Acids Res. 10:32493260.

Ti, G.S., Gaffney, B.L., and Jones, R.A. 1982. Transient protection: Efficient one-flask syntheses of protected deoxynucleosides. J. Am. Chem. Soc. 104:1316-1319.

Ushioda, M., Kadokura, M., Moriguchi, T., Kobori, A., Aoyagi, M., Seio, K., and Sekine, M. 2002. Unique participation of unprotected internucleotidic phosphodiester residues on unexpected cleavage reaction of the Si-O bond of the diisopropylsilandiyl group used as a linker for the solid-phase synthesis of $5^{\prime}$-terminal guanylated oligodeoxynucleotides. Helv. Chim. Acta 85:2930-2945.
Venner, H. 1964. Studies on nucleic acids. IX. Stability of the $\mathrm{N}$-glycosidic linkage in nucleosides. Z. Physiol. Chem. 339:14-27.

Venner, H. 1966. Research on nucleic acids. XII. Stability of the N-glycoside bond of nucleotides. Z. Physiol. Chem. 344:189-196.

Ven'yaminova, A.G., Komarova, N.I., Levin, A.S., and Repkova, M.N. 1988. Synthesis of ribonucleoside- $3^{\prime}$ - and $-5^{\prime}-H$-phosphonates via salicylchlorophosphine. Bioorg. Khim. 14:484489.

Wada, T. and Sekine, M. 1995. Chemical synthesis of oligothymidylate having hydroxymethylphosphonate internucleotidic linkages. Tetrahedron Lett. 36:845-848.

Wada, T., Sato, Y., Honda, F., Kawahara, S., and Sekine, M. 1997. Chemical synthesis of oligodeoxyribonucleotides using $\mathrm{N}$-unprotected $\mathrm{H}$-phosphonate monomers and carbonium and phosphonium condensing reagents: O-Selective phosphonylation and condensation. J. Am. Chem. Soc. 119:12710-12721.

Wada, T., Kobori, A., Kawahara, S., and Sekine, M. 1998a. Synthesis and properties of oligodeoxyribonucleotides containing 4- $\mathrm{N}$-acetylcytosine bases. Tetrahedron Lett. 39:6907-6910.

Wada, T., Mochizuki, A., Sato, Y., and Sekine, M. 1998b. Functionalization of solid supports with $\mathrm{N}$-unprotected deoxyribonucleosides. Tetrahedron Lett. 39:5593-5596.

Wada, T., Honda, F., Sato, Y., and Sekine, M. 1999. First synthesis of $H$-phosphonate oligonucleotides bearing $\mathrm{N}$-unmodified bases. Tetrahedron Lett. 40:915-918.

Wada, T., Kobori, A., Kawahara, S., and Sekine, M. 2001a. Synthesis and hybridization ability of oligodeoxyribonucleotides incorporating $\mathrm{N}$-acyldeoxycytidine derivatives. Eur. J. Org. Chem. 4583-4593.

Wada, T., Mochizuki, A., Higashiya, S., Tsuruoka, H., Kawahara, S., Ishikawa, M., and Sekine, M. 2001b. Synthesis and properties of 2-azidodeoxyadenosine and its incorporation into oligodeoxynucleotides. Tetrahedron Lett. 42:9215-9219.

Watanabe, K.A. and Fox, J.J. 1966. Simple method for selective acylation of cytidine on the 4-amino group. Angew. Chem. Int. Ed. Engl. 5:579-580.

Yamana, K., Nishijima, Y., Negishi, K., Yoshiki, T., Nishio, K., and Nakano, H. 1991. Deoxyribonucleoside 3'-phosphorobisamidites in the synthesis of isopropyl phosphotriester oligodeoxyribonucleotide analogs. Tetrahedron Lett. 32:4721-4724.

Yoshikawa, M. and Kato, T. 1967. Studies of phosphorylation. I. Phosphorylation of $2^{\prime}, 3^{\prime}-O$ isopropylidene nucleoside by phosphoryl chloride. Bull. Chem. Soc. Jpn. 40:2849-2853.

Yuodka, Y., Lunsford, W.B., and Letsinger, R.L. 1976. Oligonucleotides and nucleotidepeptides. XXV. New method for the synthesis of oligonucleotides. Bioorg. Chem. 2:12181324.
DNA Synthesis

Without Base

Protection

3.10.14 
Internet Resource

http://www.chfi.unipd.it/-chor/wisor/ lecture_notes/Bagno_acidbase.pdf

A list of the basicity of common solvents, maintained by A. Bagno, Centro CNR, Padova, Italy.

Contributed by Mitsuo Sekine

Tokyo Institute of Technology

Yokohama, Japan

Synthesis of

Unmodified

Oligonucleotides

3.10.15 